\title{
Main Problems and Future Prospects of Environmental Supervision in Guangdong-Hong Kong-Macau Grand Bay Area
}

\author{
Ying Ren \\ Green Development Law Research Center, Guangdong University of Foreign Studies, Guangzhou, China \\ Email: 2052614426@qq.com
}

How to cite this paper: Ren, Y. (2020). Main Problems and Future Prospects of Environmental Supervision in GuangdongHong Kong-Macau Grand Bay Area. Chinese Studies, 9, 53-64. https://doi.org/10.4236/chnstd.2020.92005

Received: March 18, 2020

Accepted: May 4, 2020

Published: May 7, 2020

Copyright () 2020 by author(s) and Scientific Research Publishing Inc. This work is licensed under the Creative Commons Attribution International License (CC BY 4.0).

http://creativecommons.org/licenses/by/4.0/

\section{(c) (i) Open Access}

\begin{abstract}
The article expounds the problems existing in the field of coordinated environmental supervision of Guangdong-Hong Kong-Macau Grand Bay Area, analyzes the legal problems existing in the field of environmental supervision and the reasons for the imbalance of the innovative governance structure from the perspective of the inadequate adaptability reform of the environmental supervision system and the insufficient innovation power of the environmental governance theory. This paper puts forward countermeasures and suggestions to further improve the supporting mechanism of environmental supervision in Guangdong-Hong Kong-Macau Grand Bay Area under the environmental protection law, and to strengthen the construction of environmental supervision and security system in this area in combination with supervision socialization and the revision of the administrative supervision law. In order to complete the research task well, this paper selects the research methods of system analysis and literature analysis.
\end{abstract}

\section{Keywords}

Guangdong-Hong Kong-Macau Grand Bay Area, Environmental Supervision, Future Prospects

\section{Introduction}

Collaborative environmental governance is the focus of environmental governance research at home and abroad. From the environmental cooperation between Hong Kong and Guangdong in 1990, the deepening of environmental cooperation under the framework of CEPA, to the signing of the Pan Pearl River Delta regional environmental protection cooperation agreement in 2005, the 
cross regional environmental protection cooperation and collaborative innovation research under the "one country, two systems" has a good foundation. However, the research from the perspective of environmental supervision in the mainland, Hong Kong and Macao is very deficient, which will fundamentally restrict the effective treatment of cross regional pollution transfer and evasion. Most of the researches focus on the research of regional coordination under the background of single system. While the research on the mechanism of coordinated governance under "One Country, Two Systems" is insufficient. Therefore, this paper focuses on environmental supervision in Guangdong-Hong KongMacau Grand Bay Area to discuss the main problems and future prospects of its development.

The legal cooperation mechanism of environmental supervision in Guangdong-Hong Kong-Macau Grand Bay Area is an important requirement to promote the in-depth cooperation between Guangdong, Hong Kong and Macao. The report of the 19th National Congress of the Communist Party of China stressed that we should focus on the construction of Guangdong-Hong KongMacau Grand Bay Area, form a new mechanism of three regional cooperation, and promote the integrated development of Hong Kong, Macao and the mainland. In this context, it is of great significance to deeply analyze the problems faced by the construction of legal cooperation mechanism of environmental supervision in Guangdong-Hong Kong-Macau Grand Bay Area, grasp the accurate positioning of the times, and make clear the corresponding policy views. Actually, "Bay area economy" plays an irreplaceable role with its strong agglomeration spillover function and efficient resource allocation ability, and also faces the dilemma of cross administrative division governance. From the most dynamic urban agglomerations in the Asia Pacific region to world-class urban agglomerations, the promotion of the strategic position of Guangdong-Hong Kong-Macau Grand Bay Area puts forward higher requirements for the construction of coordination mechanism across administrative divisions. Meanwhile, it also needs to optimize the setting of administrative divisions, provide a strong guarantee for regional cooperation and coordinated development, and crack the background of non single system and different legal systems. Thus we should rationalize the governance system and improve the collaborative governance structure.

The more developed the bay area economy is, the more prominent the contradiction arises between economy and environment. Therefore, the key to test the Bay Area governance lies in the construction of Environmental supervision capacity, special law enforcement inspection and innovation of Environmental supervision system. In this context, the coordinated management of environmental supervision in Guangdong-Hong Kong-Macau Grand Bay Area is promoted under the reform of national supervision system and the evaluation of the implementation of the new environmental protection law. From the 25th meeting of the Standing Committee of the 12th National People's Congress in December 2016 to the first deliberation of the State Supervision Law (Draft) at the 
28th meeting of the Standing Committee of the 12th National People's Congress in June 2017, the regulatory governance pattern has undergone a historic change. The adaptive reform of Environmental supervision in Guangdong-Hong KongMacau Grand Bay Area needs to be solved.

In 2018, the State Council issued the plan for further deepening the reform and opening up of China (Guangdong) pilot Free Trade Zone, which is based on building a new open economic system pilot area, a high-level gateway hub for opening up and a demonstration zone for cooperation between Guangdong, Hong Kong and Macao. It puts forward specific requirements for building a fair and honest legal environment, and emphasizes the implementation of the report of the 19th National Congress for mutual benefit between Guangdong, Hong Kong and Macao overall layout of cooperation. The legal cooperation mechanism of environmental supervision in Guangdong-Hong Kong-Macau Grand Bay Area is the top priority of the construction of Guangdong, Hong Kong and Macao deep cooperation demonstration area, and also the opportunity to promote the integrated development. Quality improvement and upgrading of urban agglomeration in Guangdong-Hong Kong-Macau Grand Bay Area in the process of promoting the existing CEPA pilot comprehensive demonstration area plays an important role in the modernization of governance. Policies and measures to facilitate the development of Hong Kong and Macao residents and relevant reform and innovation achievements have been continuously launched, such as taking the origin official health certificate and other certification materials approved by the competent authorities of Hong Kong and Macao as the basis for inspection and Quarantine Release, implementing fast port release for food that meets the requirements and shortening the port supervision process. These innovative measures have laid an important foundation for the cooperation of environmental supervision in Guangdong-Hong Kong-Macau Grand Bay Area. However, with the deepening of cooperation between Guangdong, Hong Kong and Macao, the importance of upgrading from the original CEPA framework to in-depth cooperation in the bay area is increasingly prominent. Accordingly, how to improve the legal cooperation mechanism of Environmental supervision in Guangdong-Hong Kong-Macau Grand Bay Area and to form a legal and convenient environment for Environmental supervision has become an important opportunity for in-depth cooperation between the mainland and Hong Kong and Macao (Matthes, 2011).

In terms of policy, Guangdong-Hong Kong-Macau Grand Bay Area is the most open area in China, which has many resources and development advantages. Under the background of "One Belt, One Road" construction and the profound changes in East Asian situation, the construction of the cooperation mechanism of environmental supervision in the area of Guangdong, Hong Kong and Macau has laid a solid foundation for national construction and international exchanges. At the same time, in the international and domestic pattern, it has important policy significance and practical value to reshape the new role of 
the three regions and accurately position the correct direction of the construction of the three regions' cooperation mechanism (Holovkin, 2011). Specifically, Hong Kong will give full play to its advantages of international financial center and build an international legal and dispute settlement service center in the Asia Pacific region; Macao will give full play to its advantages in international economic and trade cooperation platform and tourism. On this basis, we need to deepen financial cooperation between Guangdong, Hong Kong and Macao and promote the development of commodity trade in the three regions.

\section{Problems of Environmental Supervision in Guangdong-Hong Kong-Macau Grand Bay Area}

\subsection{Absence of Environmental Supervision Standards and Implementation System in Guangdong-Hong Kong-Macau Grand Bay Area}

On the one hand, most of the existing research results focus on the relationship between economic development and environmental recovery in the bay area, but do not fundamentally explore the effective environmental governance system and collaborative mechanism support. On the other hand, the existing research results mainly focus on environmental protection cooperation and management innovation research, but do not analyze the scientific path of environmental supervision collaborative governance from the particularity of Guangdong Hong Kong Macao Bay area under "one country, two systems". Therefore, on the whole, in the context of the reform of the national supervision system, the existing cohesion and coordination mechanism needs to make adaptive reform (Richard, 1985). Taking environmental supervision as the starting point, we should comprehensively improve the system and mechanism guarantee of Guangdong Hong Kong Macao in-depth cooperation, and form an effective cohesion mechanism from information sharing, public participation, environmental supervision, deliberation and coordination.

In the field of environmental supervision in Guangdong-Hong Kong-Macau Grand Bay Area, there has not been a standard system of environmental supervision which is connected with the national supervision law, an implementation system of environmental supervision which is combined with the national supervision system or an environmental supervision security system which is combined with the supervision socialization. And with the establishment and improvement of these systems, we can promote the improvement of collaborative governance pattern in the field of Environmental supervision. The key point is to solve the conflict between environmental supervision laws and regulations. While, with the transformation from administrative supervision to national supervision, the operation of supervision power is no longer subordinate to the administrative law enforcement power. Accordingly, the environmental supervision stipulated in Article 2 of the Environmental Supervision Measures refers to the administrative law enforcement activities implemented by the competent 
environmental protection authorities according to the environmental protection laws and regulations. Article 3 stipulates that for the specific administrative acts such as environmental administrative punishments made by the people's government at or above the county level or its competent department of environmental protection according to law are under supervision. And the environmental supervision organization of the competent department of environmental protection of the people's government at or above the county level shall be responsible for the specific supervision after the implementation of environmental administrative law. But the Environmental supervision standards and implementation system in Guangdong-Hong Kong-Macau Grand Bay Area is absent in legal provisions, which brings great difficulties to environmental governance.

\subsection{The Conflict of Legislation and System Mechanism in Cross Legal Environmental Supervision Cooperation}

There is still a gap in further optimizing the function allocation of environmental supervision in Guangdong-Hong Kong-Macau Grand Bay Area. So we should promote the connection of supervision, inspection, implementation and responsibility investigation based on the revision of existing laws and regulations; promote the coordination of environmental supervision and national supervision system reform based on the reform of responsibility system. Meanwhile, Guangdong-Hong Kong-Macau Grand Bay Area, with the Chinese legal system, the common law system and the continental legal system as the sources, apply different environmental protection laws and regulations respectively, which makes it difficult to effectively connect the environmental supervision cooperation among the three regions. In addition, the existing Environmental supervision cooperation research focuses on the regional coordination under the background of a single system, resulting in the research and practice of the cooperation mechanism under the "One Country, Two Systems" that are insufficient. Meanwhile, the world's Environmental supervision cooperation research focuses on the inner structure of the economic development of the Bay Area, but not fundamentally explores the effective Environmental supervision cooperation system and mechanism support. The key point is to solve the conflict between the legal norms of environmental supervision cooperation. In the context of the reform of the national supervision system, the coordination between the environmental supervision system and the national supervision system, as well as the relevant laws and regulations has become increasingly prominent, and the investigation and research on solving this governance dilemma is still lagging behind.

\subsection{The Insufficient Effectiveness and Operability of the Coordinated Management of Environmental Supervision in Guangdong-Hong Kong-Macau Grand Bay Area}

The insufficient effectiveness and operability of the coordinated management of environmental supervision in Guangdong-Hong Kong-Macau Grand Bay Area is prominent. In the absence of the integration of Environmental supervision 
and environmental supervision, the effective management mode of cracking down on local protectionist intervention has not been formed. Specifically, the implementation of environmental protection laws and regulations, as well as the inspection of environmental protection law enforcement, ecological environment supervision, post environmental law enforcement supervision and listing supervision are not coordinated enough. The problems can be divided into two aspects: one is that the supervision of enterprises' performance of environmental protection policies, plans, laws, administrative regulations, departmental rules and standards is not in place; the other is that the supervision of the government, law enforcement departments' administrative inaction is not in place. In the context of the reform of the national supervision system, the environmental supervision system with the core of the competent environmental protection department of the people's government at a higher level and the specific administrative acts such as environmental administrative punishments and orders made to the competent environmental protection department of the people's government at a lower level also needs to make corresponding adjustments. At the same time, we need to promote the connection of supervision, inspection and implementation of Guangdong-Hong Kong-Macau Grand Bay Area environmental supervision institutions, as well as the organic coordination with the national supervision system.

Different from the existing three Bay areas in the world, the construction of Guangdong, Hong Kong and Macao Bay area is related to the regional coordinated governance with different economic and social backgrounds under the "One Country, Two Systems". Neither the scale of construction nor the problems faced are unprecedented. Due to the particularity of Guangdong, Hong Kong and Macao, the political and social path dependence of environmental governance shows different characteristics; the adaptability reform of the coordinated governance mechanism of environmental supervision has become an important problem to be solved.

\section{Analysis on the Main Problems of Environmental Supervision in Guangdong-Hong Kong-Macau Grand Bay Area}

\subsection{The Legal Problems in the Field of Environmental Supervision}

The legal problems in the field of environmental supervision have not been effectively solved

The existing environmental supervision is mainly carried out within the framework of the environmental protection law, the administrative supervision law, the environmental supervision measures and the supervision measures taken after environmental administrative law enforcement. However, when the contradictions among the national supervision law, the provisions on the functions of environmental supervision institutions and the environmental administrative law enforcement supervision measures become more prominent, in prac- 
tice, there will be many problems such as false data, mobile surprise inspection. And the interdepartmental inspection is lack of cooperation mechanism's guarantee. The new environmental protection law puts forward stricter requirements for environmental supervision but those requirements have not been fully implemented in practice (Yevstigneyev, 2014).

The legal and other practical problems that hinder the cooperation of environmental supervision in the three regions need to be solved urgently. The legal cooperation of environmental supervision in Guangdong-Hong Kong-Macau Grand Bay Area needs not only to be promoted with the solution of the contradictions and conflicts of cross legal system cooperation from the theoretical level, but also to be explored with the scientific methods to effectively remove the obstacles of environmental supervision cooperation in three areas from the practical level. Meanwhile, the problems to be solved in this process are not only legal problems, but also many related policy system problems, economic development and social problems. It is not enough to explore the solutions to the problems involved in this subject only by a single research method of a certain discipline. It is necessary to organically combine the natural science with the analytical methods of social science, economy and management, administration and law, so as to lay a solid foundation for the removal of the obstacles to the cooperation of environmental supervision in Guangdong-Hong Kong-Macau Grand Bay Area, and establish the cooperation mechanism of environmental supervision under the rule of law.

\subsection{Imbalance of Environmental Supervision and Control Structure in Guangdong-Hong Kong-Macau Grand Bay Area}

The transformation from administrative supervision to state supervision is a great innovation of the theory of state governance in China, and also puts forward new requirements for the development of the theory of rule of law. In this context, the Environmental supervision and management structure of Guangdong Hong Kong Macao Bay area is facing two major problems, which are adaptive reform and innovative development.

On one hand, the theoretical innovation power of environmental supervision and governance is insufficient. From the perspective of governance, the research on the legal issues of environmental supervision should be guided by the innovation of governance theory. Starting from the legalization of environmental supervision and governance, the transformation from mobile environmental supervision to standardized supervision and responsibility supervision should be realized. From the perspective of supervision function, supervision procedure, system connection and responsibility investigation, a new thinking and new method to solve the problems in the field of environmental supervision can be formed.

On the other hand, the adaptive reform of Environmental supervision system is not in place. From a more fundamental point of view, the dilemma of envi- 
ronmental supervision governance in practice reflects the problems existing in the construction of environmental supervision system. From the perspective of governance, it is of great theoretical significance to adapt to the reform of national supervision system, and explore the path of environmental supervision system reform.

\section{Mechanism Guarantee and Future Prospect of Environmental Supervision in Guangdong-Hong Kong-Macau Grand Bay Area}

\subsection{The Standard Guarantee of Coordinated Management of Environmental Supervision in Guangdong-Hong Kong-Macau Grand Bay Area}

Standard guarantee is preconditions for smooth progress of the environmental supervision in Guangdong-Hong Kong-Macau Grand Bay Area. Under the background of the revision of the administrative supervision law, we will promote the fundamental solution of the environmental supervision and governance problems in Guangdong-Hong Kong-Macau Grand Bay Area. With the acceleration of the transformation process from the administrative supervision law to the national supervision law, the revision of corresponding laws and regulations needs to be put on the agenda. At the same time, in the field of Environmental supervision in Guangdong-Hong Kong-Macau Grand Bay Area, conflicts between existing norms need to be resolved thoroughly, and the connection of supervision, inspection, supervision, implementation and accountability needs to be completed. Among them, the most prominent one is the conflict of legal norms, including legal functions and their attributes, of environmental supervision in Guangdong-Hong Kong-Macau Grand Bay Area (Adeniji, 1975). Based on the formulation, modification and cleaning up of legal norms, solving the legal problems in the field of environmental supervision in GuangdongHong Kong-Macau Grand Bay Area has become the top priority in the reform of environmental supervision in Guangdong-Hong Kong-Macau Grand Bay Area.

Guangdong-Hong Kong-Macau Grand Bay Area is the only one of the four Bay areas in the world that spans three different legal systems and operates under different systems. Thus its regional environment coordinated governance has very distinct characteristics. To some extent, there is no precedent for solving the problems it faces. The differences between Guangdong, Hong Kong and Macao are not only reflected in the legal level, such as socialist legal system with Chinese characteristics, common law system and civil law system, but also in the political and economic system, administrative system, specific policies and standards, and even in the social and public awareness. Accordingly, taking Environmental supervision as the starting point, promoting legislative coordination, system docking, case transfer and people's integration is not only an important guarantee for the connectivity and overall coordination of Guangdong-Hong Kong-Macau Grand Bay Area, but also a basic premise for the smooth operation 
of the bay area. This is different from other Bay areas in the world. For example, based on the development of the bay area, Tokyo Bay area Environmental supervision and management promote the innovative development of environmental protection measures. However, unlike the decentralized environmental administrative supervision in the common law system, Japan has established a vertical management system from the central government to the local government, which lays the institutional foundation for the formation of a centralized and systematic environmental supervision force. The American supervision system is limited to the administrative law enforcement level. Under the federal system, each state is responsible for the promotion of Environmental supervision, and there are Bay Area Committees to deal with cross regional environmental issues. While there is no unified monitoring system, an Environmental supervision system with environmental litigation as the core has been formed and only limited to the level of administrative supervision of environmental law enforcement combined with litigation centralism. In the development process of the Bay areas, the tension between economic development mode and specific environmental problems has been highlighted. The bay areas are driven by port economy and science and technology. The corresponding environmental governance and collaborative system construction must also reflect the regional differences as the basis of Environmental supervision, and break the limitations of generalized collaborative governance.

\subsection{Mechanism Guarantee of Coordinated Management of Environmental Supervision in Guangdong-Hong Kong-Macau Grand Bay Area}

Mechanism guarantee is important guarantee for smooth operation of the environmental supervision in Guangdong-Hong Kong-Macau Grand Bay Area. We need to further improve the support of the Environmental supervision mechanism of Guangdong-Hong Kong-Macau Grand Bay Area in the environmental protection law. The new law on environmental protection defines the legal status of supervisory organs. The second paragraph of Article 57 stipulates that citizens, legal persons and other organizations shall have the right to report to their higher authorities or supervisory organs if they find that local people's governments at all levels, competent environmental protection departments of people's governments at or above the county level and other departments which are responsible for environmental protection supervision and management fail to perform their duties according to law (Agostini \& Ferreira, 2015). Article 67 stipulates that the people's government at a higher level and its competent environmental protection departments shall strengthen supervision over the environmental protection work of the people's government at a lower level and its relevant departments. If it is found that the relevant staff member has committed an illegal act and should be punished according to law, it shall make suggestions to the appointment and removal organ or the supervisory organ. However, in 
the more than two years since the implementation of the environmental law in 2015, the construction of Environmental supervision supporting mechanism has lagged behind obviously. It is of great practical significance to promote the settlement of the mechanism problems of environmental supervision in Guangdong-Hong Kong-Macau Grand Bay Area. From a more fundamental level, the transformation from benefit value to ecological value has become a bridge combining Environmental supervision and industrial cluster development. With the development of human society and economy and the promotion of industrialization, the ecological load and cost of economic and social development continue to increase. Many countries have adopted administrative, legal, technical and other ways to promote the transformation of their own development mode. Through the value accounting of ecological capital (evaluation of positive and negative effects of social economy) and the development strategy of green national economy, promoting the relationship between supply and demand of commodity value to the advanced level of the relationship between supply and demand of ecological value has become an important basis for the accurate positioning of regional Environmental supervision and the free flow and dislocation development of elements. Guangdong, Hong Kong and Macao are the important engines of national economic development.

\subsection{Social Security of Coordinated Management of Environmental Supervision in Guangdong-Hong Kong-Macau Grand Bay Area}

Social security is realistic soil for practical realization of the environmental supervision in Guangdong-Hong Kong-Macau Grand Bay Area. We need to strengthen the construction of an Environmental supervision and security system in Guangdong-Hong Kong-Macau Grand Bay Area that integrates supervision and socialization. The environmental supervision and guarantee system mainly includes two aspects: one is the protection of people, property and occupation, the other is the legalization of responsibility, including the reverse check of responsibility. Environmental problems involve a wide range and often have the characteristics of concealment. Therefore, the establishment and improvement of an effective environmental security system cannot be separated from the support of supervision socialization. Here is the problem of dealing with the relationship between environmental supervision and supervision socialization. It should be noted that environmental supervision has the attribute of public power (Klijn et al., 2009). Instead of blindly embedding the socialized supervision into the existing supervision system, it should form a multi-level and multi-field environmental supervision governance pattern. The collaborative governance of Guangdong-Hong Kong-Macau Grand Bay Area environmental supervision not only involves the enforcement of law enforcement power by Guangdong Environmental supervision Center, Hong Kong Environmental Protection Agency, Macao Environmental Protection Agency and other agencies, but also requires adaptive reform of the existing linkage and coordination system. The solution of 
their environmental problems needs to be closely combined with industrial development, so as to provide practical guarantee and support for the improvement of the effectiveness of Environmental supervision (Olson, 1984).

\section{Conclusion}

Taking environmental supervision as the starting point, we will comprehensively improve the system guarantee of Guangdong Hong Kong Macao in-depth cooperation. Its core issues include two aspects. One aspect is exploring the innovation of collaborative governance system with environmental supervision as the starting point. Starting from the effective prevention of trans-regional pollution transfer and avoidance, we need to define the scope of supervision authority and case transfer, and determine the specific link supervision responsibility system. The other aspect is the dynamic balance between the right to development and the protection of environmental rights, and promoting the rebalancing of economic development and environmental recovery in the Bay Area through the docking of personnel and institutions at the environmental supervision level. That is to say, from the perspective of supervision function, supervision procedure, system connection and responsibility investigation, a new way to solve the problem of economic and environmental coordination is formed.

\section{Fund Projects}

The 13th five year plan project of philosophy and social sciences of Guangdong Province "Research on coordinated management of environmental supervision in Guangdong Hong Kong Macao Bay Area" (GD17YFX03), Young innovative talents project of Guangdong Provincial Department of Education Research on legal issues of environmental supervision from the perspective of governance (2017WQNCX036).

\section{Conflicts of Interest}

The authors declare no conflicts of interest regarding the publication of this paper.

\section{References}

Adeniji, K. (1975). The Legal Challenge of Environmental Pollution to Africa: A Case Study in the Regional Approach to Environmental Problems. Anglo-American Law Review, 3, 312. https://doi.org/10.1177/147377957500400306

Agostini, A.M., \& Ferreira, H. S. (2015). Citizen Supervision: From the Construction of the Concept of Citizenship to the Effectiveness of Its Exercise by Means of the Supervision of Environmental Infractions. Veredas do Direito, 23, 91.

Holovkin, O. (2011). The State Control and Supervision in the Sphere of Environmental Protection as a Component of Environmental Policy of Ukraine, Agricultural, Land and Environmental Law. Law Review of Kyiv University of Law, 4, 290.

Klijn, A.-M., Gupta, J., \& Nijboer, A. (2009). Privatizing Environmental Resources: The Need for Supervision of Clean Development Mechanism Contracts. Review of Euro- 
pean, Comparative \& International Environmental Law, 18, 172.

https://doi.org/10.1111/j.1467-9388.2009.00639.x

Matthes, R. A. (2011). Extra Supervision as a Tool for Environmental Protection in Brazil. Veredas do Direito, 16, 47.

Olson, E. D. (1984). The Quiet Shift of Power: Office of Management and Budget Supervision of Environmental Protection Agency Rulemaking under Executive Order 12,291. Virginia Journal of Natural Resources Law, 1, 2.

Richard, L. (1985). Challenges to Presidential Supervision of Environmental Rulemaking. Hofstra Environmental Law Digest, 2, 22.

Yevstigneyev, A. (2014). Legal Problems of State Supervision for the Provision of Ecological Safety during Special Subsoil Use in Ukraine, Agricultural, Land and Environmental Law. Review of Kyiv University of Law, 2, 253. 